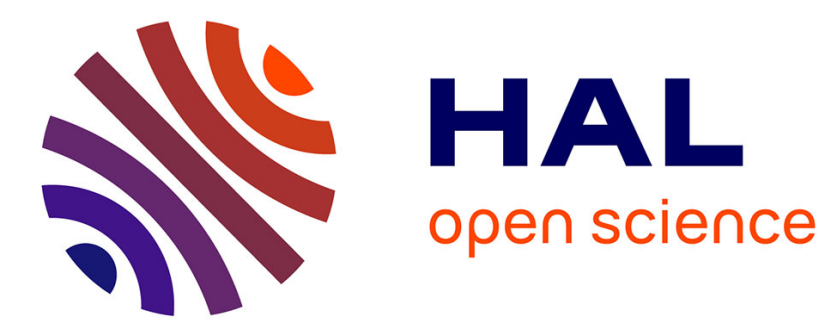

\title{
Stereotype Threat Strengthens Automatic Recall and Undermines Controlled Processes in the Elderly
}

Marie Mazerolle, Isabelle Régner, Pauline Morisset, François Rigalleau, Pascal Huguet

\section{- To cite this version:}

Marie Mazerolle, Isabelle Régner, Pauline Morisset, François Rigalleau, Pascal Huguet. Stereotype Threat Strengthens Automatic Recall and Undermines Controlled Processes in the Elderly. Psychological Science, 2012, 23 (7), pp.723-727. 10.1177/0956797612437607 . hal-01341808

\section{HAL Id: hal-01341808 \\ https://hal.science/hal-01341808}

Submitted on 4 Jul 2016

HAL is a multi-disciplinary open access archive for the deposit and dissemination of scientific research documents, whether they are published or not. The documents may come from teaching and research institutions in France or abroad, or from public or private research centers.
L'archive ouverte pluridisciplinaire HAL, est destinée au dépôt et à la diffusion de documents scientifiques de niveau recherche, publiés ou non, émanant des établissements d'enseignement et de recherche français ou étrangers, des laboratoires publics ou privés. 
Stereotype Threat Strengthens Automatic Recall and

Undermines Controlled Processes in the Elderly

Marie Mazerolle ${ }^{1}$, Isabelle Régner ${ }^{2}$, Pauline Morisset $^{1}$, François Rigalleau $^{1}, \&$ Pascal Huguet $^{2}$

${ }^{1}$ Université de Poitiers \& Centre de Recherche sur la Cognition et l'Apprentissage (CNRS, UMR 6234)

${ }^{2}$ Aix-Marseille Univ \& Laboratoire de Psychologie Cognitive (CNRS, UMR 6146) 


\begin{abstract}
The threat of being judged stereotypically (stereotype threat or ST) may impair memory performance in the elderly, resulting in inflated age differences in memory tasks. However, the underlying mechanisms of ST in the elderly or other stigmatized groups remain poorly understood. Here, we offer evidence that ST consumes working memory resources in the elderly. More importantly, we rely on a process dissociation procedure (PDP) and show for the first time that ST undermines the controlled use of memory and simultaneously intensifies automatic response tendencies. These new findings indicate that seemingly concurrent models of ST are actually compatible, and offer further reasons to pay special attention to aging stereotypes during standardized neuropsychological testing.
\end{abstract}

KEY WORDS: Stereotype Threat, Aging, Memory, Automatic and Controlled Processes 
Stereotype Threat Strengthens Automatic Recall and

Undermines Controlled Processes in the Elderly

According to the November 27, 2010 edition of Science Daily, in just a few decades there will be more elderly people than children in most parts of the world (with the exception of Africa). More and more people therefore will be concerned by the effects of aging on their mental faculties (e.g., memory decline) and with getting Alzheimer's disease or other forms of dementia, resulting in a growing demand for standardized neuropsychological testing. This demand may be exacerbated by aging stereotypes (predicting severe cognitive decline to occur with age for all people), which ironically may also lower older adults' test scores (Hess, 2005; Hess, Hinson, \& Hodges, 2009; for a review see, Kit, Tuokko, \& Mateer, 2008). The elderly may find neuropsychological testing, especially screenings for memory problems, very threatening for a variety of reasons including stereotype threat (ST).

ST refers to the possibility that one's performance will confirm - to others and/or oneself - a negative stereotype about one's group abilities (Steele, 1997), a threat that may occur in young adults (Schmader, Johns, \& Forbes, 2008) and children as well (e.g., Huguet \& Régner, 2007, 2009). Previous research in the elderly, showed that this situational threat significantly impaired memory performance (free, cued and/or recognition-based recall) when the memory component of the test was emphasized (Desrichard \& Köpetz, 2005; Kang \& Chasteen, 2009; Rahhal, Hasher, \& Colcombe, 2001), when performance differences between younger and older adults were highlighted (Hess et al., 2009; Hess, Auman, Colcombe, \& Rahhal, 2003), and when the aging stereotype about memory was implicitly activated using priming techniques (Levy, 1996; Stein, Blanchard-Fields, \& Hertzog, 2002). In all these studies, reduced threat was associated with reduced difference in performance between older and younger participants, with sometimes no difference at all (Desrichard \& Köpetz, 2005, 
Study 2; Hess et al., 2003), indicating how powerful aging stereotypes can be. Older adults seem to be more susceptible to ST effects when they are highly educated (Hess et al., 2009), high in stigma consciousness or perceived ST (Hess et al., 2009; Kang \& Chasteen, 2009), and when they value memory ability (Hess et al., 2003). Thus, there is today little doubt that ST may, at least in part, account for age differences in memory tasks.

\section{THE PRESENT RESEARCH}

Although the occurrence of ST in the elderly is now well-documented, the underlying mechanisms remain poorly understood. The few studies in this area show that ST may operate by lowering performance expectations (e.g., Desrichard \& Köpetz, 2005) and/or the use of memory strategies (e.g., Hess et al., 2003). As suggested by Hess et al. (2003), because strategy use requires executive control resources such as those involved in working memory (Engle, 2002), ST might reflect temporary reductions of working memory (WM) capacity. Only one study addressed this hypothesis so far in the elderly (Hess et al., 2009) but failed to show any reduction of WM capacity under ST. And yet, there is evidence in young adults facing stereotypes (e.g., women on math tests) that ST taxes WM resources required for successful performance on many difficult tasks (e.g., Beilock, Rydell, \& McConnell, 2007; Régner et al., 2010; Rydell, McConnell, \& Beilock, 2009; Schmader \& Johns, 2003; for a review, see Schmader et al., 2008). We propose that as for young adults, ST induced by the salience of memory stereotype in the testing situation should impair older adults WM capacity.

According to Schmader et al. integrated model (2008), ST reduces WM capacity because controlled resources are allocated to the regulation of negative thoughts, emotions and appraisal processes. That is, controlled processes will be more allocated to control and monitor one's behavior rather than to the task itself. Jamieson and Harkins (2007) challenged the WM explanation of ST effects with their mere effort hypothesis. According to these 
authors, ST motivates individuals to do well at the task, thereby increasing activation of the prepotent response (Zajonc, 1965) that is often incorrect on difficult tasks. Under ST the prepotent response will be more activated, resulting in a more automatic mode of response. However, Schmader et al. (2008) argued that the data associated with this alternative account cannot distinguish between the overproduction of a prepotent or automatic response and the failed inhibition of this response due to impaired WM resources.

Here, we offer direct evidence that ST consumes WM resources in the elderly. Perhaps more importantly, we rely on a process dissociation procedure (PDP; Jacoby, 1991; Payne, 2008) and show for the first time that ST in the elderly influences both controlled and automatic uses of memory simultaneously.

\section{METHOD}

\section{Participants}

The study sample included 112 young adults (Mage $=21.35$ years, $S D$ age $=2.85 ; 81$ females) and 112 older adults (Mage $=69.01$, SDage $=5.67 ; 71$ females) who agreed to take part in a study focusing on general mental abilities. All the older participants achieved scores over the cut-off at the Mini-Mental State Evaluation (Folstein, Folstein, \& McHugh, 1975), following specific guidelines (Crum, Anthony, Bassett, \& Folstein, 1993).

\section{Procedure}

The study was run in a single session, but participants were told that there were two separate studies. In the "first study", they completed a Reading Span task (RST; Daneman \& Carpenter, 1980), which was supposedly "under construction” to minimize evaluative pressure (no feedback was delivered). Participants were encouraged to do their very best. This first version was used to obtain a baseline for WMC. Then (« second study »), participants were told that they were going to take two memory tests: a cued recall task (i.e., PDP, see Jennings \& Jacoby, 1993, Exp1b) and another reading span task (similar in difficulty 
compared to that used as baseline), which was presented as "fully validated and diagnostic of memory capacity". For both tasks, participants were randomly assigned to one of two conditions. In the stereotype activation condition, they were simply told that both younger and older adults participated in the present study. In the age-fair condition, the presence of younger participants was mentioned, but it was also said that there is usually no difference between younger and older adults on the tests at hand.

\section{Measures}

The French version of the RST (Desmette, Hupet, Schelstraete, \& Van Der Linden, 1995) was used to assess dispositional WM. Participants read aloud 12 series of sentences containing two to five sentences ( 3 series per length). After each series, they were to recall the last word of each sentence read. WM scores were equal to the mean proportion of words correctly recalled in a series. The sentences used in the first and second RST were different and matched in terms of number of words, length, frequency, and number of syllables of the last word of each sentence.

In the cued recall task (i.e., PDP), participants were given a list of 40 words and were instructed to read words aloud and remember them for a later memory phase. Each word appeared for $1.5 \mathrm{~s}$, followed by $0.5 \mathrm{~s}$ of blank screen. Then, 80 word stems were presented one at a time as the initial three letters of a word, participants had to complete each stem based on either a word pertaining to the list presented earlier (inclusion recall condition) or a new word (exclusion recall condition). Word stems appeared in either blue or red and were randomly presented. Participants were told that if the stem appeared in blue, there was to use it as a cue to help them remember a word that was presented earlier (inclusion condition). If they could not think of an old word, they were to complete the stem with the first word that came to mind. Participants were told to also use red stems as a cue for remembering words presented earlier but that they were to complete those stems with a word that was not 
presented earlier (exclusion condition). Because ST typically occurs on difficult tasks, participants were not informed of their errors and had no second chance (i.e., they could not generate an alternative in case of error). Participants were allowed a maximum of $15 \mathrm{~s}$ to complete each stem, but could say "pass" at any time during the $15 \mathrm{~s}$ if they felt they could not complete the stem.

Performance in the inclusion and exclusion conditions provided a means of estimating the contribution of controlled and automatic processes in recall. Following Jacoby's formulas, the probability of controlled recollection $(R)$ was estimated as the difference between inclusion and exclusion ( $R=$ inclusion - exclusion $)$. The probability of automatic influences thus was estimated by $A=\operatorname{exclusion} /(1-R)$.

\section{RESULTS}

\section{Working memory}

We conducted a Test instructions (stereotype activation vs. age-fair) by Age (younger vs. older) Analysis of Covariance (ANCOVA) using participants' performance at the second RST as dependent variable, while controlling for their performance at the first RST and its interaction with Test instructions (Yzerbyt, Muller, \& Judd, 2004). Not surprisingly, the younger participants $(M=.78, S E=.01)$ performed better than their older counterparts $(M=$ $.75, S E=.01), F(1,214)=8.52, p<.004, \eta^{2}=.04$. In addition, participants performed better in the age-fair condition $(M=.77, S E=.01)$ than in the stereotype activation condition $(M=$ $.75, S E=.01), F(1,214)=4.57, p<.04, \eta^{2}=.02$. More importantly, this analysis also showed a Test instructions by Age interaction, $F(1,214)=4.85, p<.03, \eta^{2}=.02$. Whereas the older participants performed lower in the stereotype activation condition $(M=.73, S E=.01)$ than in the age-fair condition $(M=.77, S E=.01), F(1,214)=9.42, p<.002, \eta^{2}=.04$, the younger participants performed equally well in both conditions $(F<1)$. In addition, whereas the older participants $(M=.73, S E=.01)$ underperformed compared to the younger participants $(M=$ 
$.78, S E=.01)$ in the stereotype activation condition, $F(1,214)=12.87, p<.001, \eta^{2}=.06$, they performed equally well in the age-fair condition $(F<1)$.

\section{Estimates of controlled recollection and automatic influences (PDP).}

Controlled recollection was estimated as the probability of responding with a studied word in the inclusion condition minus the probability of responding with a studied word in the exclusion condition. A 2 (Test instructions) x 2 (Age) ANOVA showed a main effect of Age, $F(1,216)=50.34, p<.001, \eta^{2}=.19$, indicating that the younger participants $(M=.17, S E=$ $.01)$ showed higher controlled recollection than their older counterparts $(M=.05, S E=.01)$. More importantly, this analysis also indicated the expected interaction, $F(1,216)=5.39, p$ $<.03, \eta^{2}=.02$. Whereas the older participants showed lower controlled recollection in the stereotype activation condition $(M=.02, S E=.02)$ than in the age-fair condition $(M=.08, S E$ $=.02), F(1,216)=6.83, p<.01, \eta^{2}=.03$, the younger participants performed equally well in both conditions $(F<1)$.

Automatic influences were estimated as the probability of responding with a studied word in the exclusion condition divided by 1 minus $R$ (i.e., inclusion - exclusion). The same 2 x 2 ANOVA as before showed a main effect of Test instructions, $F(1,216)=8.57, p<.004$, $\eta^{2}=.04$, indicating that the automatic use of memory was greater in the stereotype activation condition $(M=.15, S E=.01)$ than in the age-fair condition $(M=.12, S E=.01)$. Again, the interaction was significant, $F(1,216)=4.49, p<.04, \eta^{2}=.02$. Whereas the older participants showed greater automatic use of memory in the stereotype activation condition $(M=.17, S E=$ $.01)$ than in the age-fair condition $(M=.11, S E=.01), F(1,216)=12.73, p<.001, \eta^{2}=.06$, no difference was found in the younger participants $(F<1)$. In addition, in the stereotype activation condition, the older participants $(M=.17, S E=.01)$ tended to show greater automatic use of memory than their younger counterparts $(M=.14, S E=.01), F(1,216)=$ $3.51, p<.06, \eta^{2}=.02$ 


\section{DISCUSSION}

ST impaired older adults' WM capacity, is consistent with earlier findings on younger adults facing other stereotypes (Schmader et al., 2008). Hess et al. (2009) failed to show a similar finding with older adults, but attributed this failure to the way they characterized their WM task ("test of quantitative skills" rather than "memory test"). Our finding strengthens the view that ST operates in older adults facing WM tasks, provided the aging stereotype about memory is made relevant for the testing situation.

More importantly, Jacoby's PDP revealed that ST simultaneously undermined the use of controlled processes and intensified the use of automatic processes. This finding helps clarify a major debate about the respective contribution of executive WM resources and prepotent responses in ST-related performance deficits. There is today ample evidence that WM is involved in the control of attention and deployment of inhibitory processes (for reviews, see Engle, 2002; Unsworth \& Engle, 2007). The lower contribution of controlled processes under ST (as indicated by the PDP) is therefore consistent with the reduction of WM in this condition. ${ }^{1}$ Taken together, our WM and PDP findings provide further evidence that ST-related performance deficits reflect a transitory reduction in executive control resources. Interestingly, ST simultaneously strengthened automatic influences (as also indicated by the PDP), which supports the alternative view that this threat may also be rooted in the overproduction of a prepotent response (Jamieson \& Harkins, 2007). In sum, the present findings strongly suggest that seemingly concurrent models of ST are actually compatible.

Finally, it is noteworthy that all manifestations of ST in our research were obtained by simply informing older participants about the presence of younger participants (without mentioning any expected age-related differences on performance). This strengthens the view that nullifying aging stereotypes is needed for valid standardized neuropsychological testing. 


\section{References}

Beilock, S. L., Rydell, R. J., \& McConnell, A. R. (2007). Stereotype threat and working memory: Mechanisms, alleviation, and spillover. Journal of Experimental Psychology: General, 136(2), 256-276. doi:10.1037/0096-3445.136.2.256

Crum, R. M., Anthony, J. C., Bassett, S. S., \& Folstein, M. F. (1993). Population-based norms for the Mini-Mental State Examination by age and educational level. The Journal of the American Medical Association, 269(18), 2386-2391. doi:10.1001/jama.1993.03500180078038

Daneman, M., \& Carpenter, P. A. (1980). Individual differences in working memory and reading. Journal of Verbal Learning and Verbal Behavior, 19, 450-466. doi:10.1016/S0022-5371(80)90312-6

Desmette, D., Hupet, M., Schelstraete, M. A., \& Van Der Linden, M. (1995). Adaptation en langue française du «Reading Span Test» de Daneman et Carpenter (1980). L'année Psychologique, 95(3), 459-482. doi:10.3406/psy.1995.28842

Desrichard, O., \& Köpetz, C. (2005). A threat in the elder: the impact of task-instructions, self-efficacy and performance expectations on memory performance in the elderly. European Journal of Social Psychology, 35, 537-552. doi:10.1002/ejsp.249

Engle, R. W. (2002). Working memory capacity as executive attention. Current Directions in Psychological Science, 11(1), 19-23. doi:10.1111/1467-8721.00160

Folstein, M. F., Folstein, S. E., \& McHugh, P. R. (1975). Mini-Mental State: a practical method for grading the cognitive state of patients for the clinician. Journal of Psychiatric Research, 12, 189-198. doi:10.1016/0022-3956(75)90026-6

Hess, T. M. (2005). Memory and aging in context. Psychological Bulletin, 131(3), 383-406. doi:10.1037/0033-2909.131.3.383

Hess, T. M., Auman, C., Colcombe, S. J., \& Rahhal, T. A. (2003). The impact of stereotype 
threat on age differences in memory performance. Journal of Gerontology: Psychological Sciences, 58 B.(1), 3-11. doi:10.1093/geronb/58.1.P3

Hess, T. M., Hinson, J. T., \& Hodges, E. A. (2009). Moderators of and mechanisms underlying stereotype threat effects on older adults' memory performance. Experimental Aging Research, 35(2), 153-177. doi:10.1080/03610730802716413

Huguet, P., \& Régner, I. (2007). Stereotype threat among schoolgirls in quasi-ordinary classroom circumstances. Journal of Educational Psychology, 99(3), 545-560. doi:10.1037/0022-0663.99.3.545

Huguet, P., \& Régner, I. (2009). Counter-stereotypic beliefs in math do not protect school girls from stereotype threat. Journal of Experimental Social Psychology, 45, 10241027. doi:10.1016/j.jesp.2009.04.029

Jacoby, L. L. (1991). A process dissociation framework: Separating automatic from intentional uses of memory. Journal of Memory and Language, 30, 513-541. doi:10.1016/0749-596X(91)90025-F

Jamieson, J. P., \& Harkins, S. G. (2007). Mere effort and stereotype threat performance effects. Journal of Personality and Social Psychology, 93(4), 544-564. doi:10.1037/00223514.93 .4 .544

Jennings, J. M., \& Jacoby, L. L. (1993). Automatic versus intentional uses of memory: Aging, attention, and control. Psychology and Aging, 8(2), 283-293. doi:10.1037/08827974.8.2.283

Kang, S. K., \& Chasteen, A. L. (2009). The moderating role of age-group identification and perceived threat on stereotype threat among older adults International. Journal of Aging and Human Development, 69(3), 201-220. doi:10.2190/AG.69.3.c

Kit, K. A., Tuokko, H. A., \& Mateer, C. A. (2008). A review of the stereotype threat literature and its application in a neurological population. Neuropsychology Review, 18(2), 132- 
148. doi:10.1007/s11065-008-9059-9

Levy, B. (1996). Improving memory in old age through implicit self-stereotyping. Journal of Personality and Social Psychology, 71(6), 1092-1107. doi:10.1037/0022-3514.71.6.1092

Payne, B. K. (2008). What mistakes disclose: A process dissociation approach to automatic and controlled processes in social psychology. Social and Personality Psychology Compass, 2(2), 1073-1092. doi:10.1111/j.1751-9004.2008.00091.x

Preacher, K. J., \& Hayes, A. F. (2004). SPSS and SAS procedures for estimating indirect effects in simple mediation models. Behavior Research Methods, Instruments, \& Computers, 36(4), 717-731. doi:10.3758/BF03206553

Rahhal, T. A., Hasher, L., \& Colcombe, S. J. (2001). Instructional manipulations and age differences in memory: Now you see them, now you don't. Psychology and Aging, 16(4), 697-706. doi:10.1037//0882-7974.16.4.697

Régner, I., Smeding, A., Gimmig, D., Thinus-Blanc, C., Monteil, J. M., \& Huguet, P. (2010). Individual differences in working memory moderate stereotype-threat effects. Psychological Science, 21(21), 1646-1648. doi:10.1177/0956797610386619

Rydell, R. J., McConnell, A. R., \& Beilock, S. L. (2009). Multiple social identities and stereotype threat: Imbalance, accessibility, and working memory. Journal of Personality and Social Psychology, 96(5), 949-966. doi:10.1037/a0014846

Schmader, T., \& Johns, M. (2003). Converging evidence that stereotype threat reduces working memory capacity Journal of Personality and Social Psychology, 85(3), 440-452. doi:10.1037/0022-3514.85.3.440

Schmader, T., Johns, M., \& Forbes, C. (2008). An integrated process model of stereotype threat effects on performance. Psychological Review, 115(2), 336-356. doi:10.1037/0033-295X.115.2.336

Steele, C. M. (1997). A threat in the air: How stereotypes shape intellectual identity and 
performance. American Psychologist, 52(6), 613-629. doi:10.1037/0003-066X.52.6.613

Stein, R., Blanchard-Fields, F., \& Hertzog, C. (2002). The effects of age-stereotype priming on the memory performance of older adults. Experimental Aging Research, 28(2), 169181. doi:10.1080/03610730252800184

Unsworth, N., \& Engle, R. W. (2007). The nature of individual differences in working memory capacity: Active maintenance in primary memory and controlled search from secondary memory. Psychological Review, 114(1), 104-132. doi:10.1037/0033295X.114.1.104

Yzerbyt, V. Y., Muller, D., \& Judd, C. M. (2004). Adjusting researchers' approach to adjustment: On the use of covariates when testing interactions. Journal of Experimental Social Psychology, 40, 424-431. doi:10.1016/j.jesp.2003.10.001

Zajonc, R. B. (1965). Social facilitation. Science, 149, 269-274.

doi:10.1126/science.149.3681.269 


\section{Footnote}

${ }^{1}$ To test whether controlled recollection mediated the effects of Test instructions on the older participants' WM (second RST), a mediation analysis was performed using a bootstrapping procedure (Preacher \& Hayes, 2004). We entered Test instructions as predictor while including our previous covariates (performance on the first RST and its interaction with Test instructions), the performance on the second RST as the dependent variable, and estimates of controlled recollection as the mediator. The analysis was set to 1000 iterations and confidence interval to $95 \%$. The total effect of Test instructions on WM performance was significant, $t(110)=-3.09, p<.003$, as well as its effect on estimates of controlled recollection, $t(110)=-3.23, p<.002$. Estimates of controlled recollection significantly predicted performance, $t(110)=-1.76, p<.08$. Finally, with estimates of controlled recollection controlled for, the direct effect of Test instructions on WM performance was still significant, $t(110)=-2.45, p=.02$, but the resulting slight drop in statistical significance was confirmed by the confidence interval that ranged from - .0094 to -.0004 . Because zero is not in this interval, it can be concluded that the interaction effect on performance was mediated by estimates of controlled recollection. 


\section{Figures captions}

Figure 1

Adjusted Reading span score by threat condition and age group. Error bars indicate standards errors of the mean.

\section{Figure 2}

Estimates of controlled processes in cued recall by threat condition and age group. Error bars indicate standards errors of the mean.

\section{Figure 3}

Estimates of automatic processes in cued recall by threat condition and age group. Error bars indicate standards errors of the mean. 
Figure 1

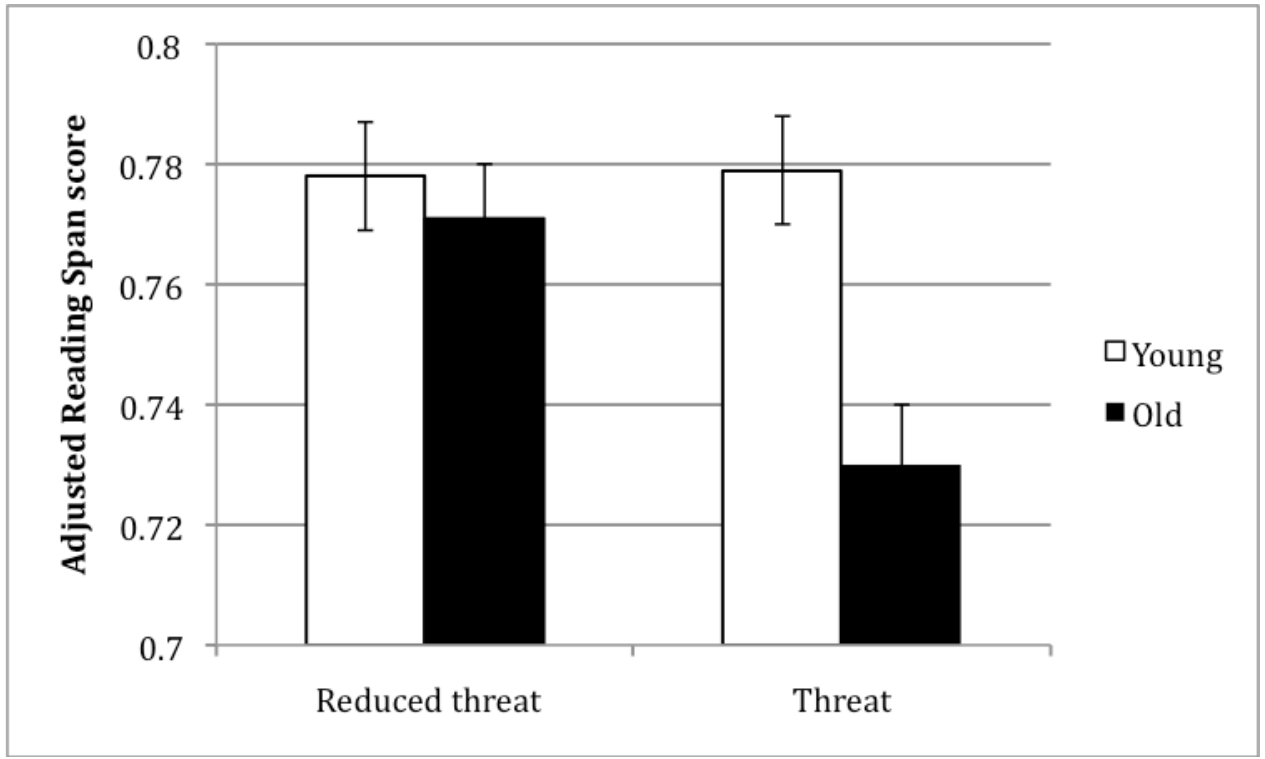

Fig. 1. Adjusted Reading Span score by threat condition and age group. Error bars indicate standards errors of the mean. 
Figure 2

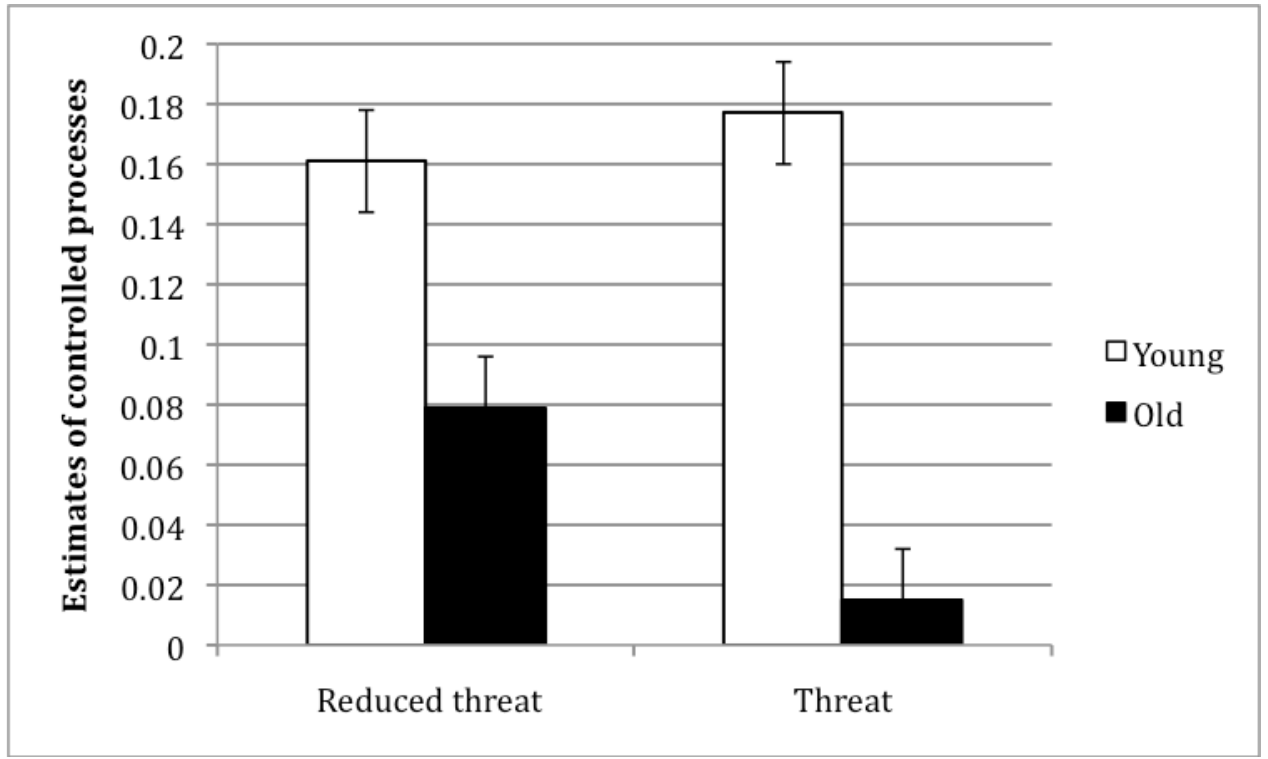

Fig. 2. Estimates of controlled influence in cued recall by threat condition and age group. Error bars indicate standards errors of the mean. 
Figure 3

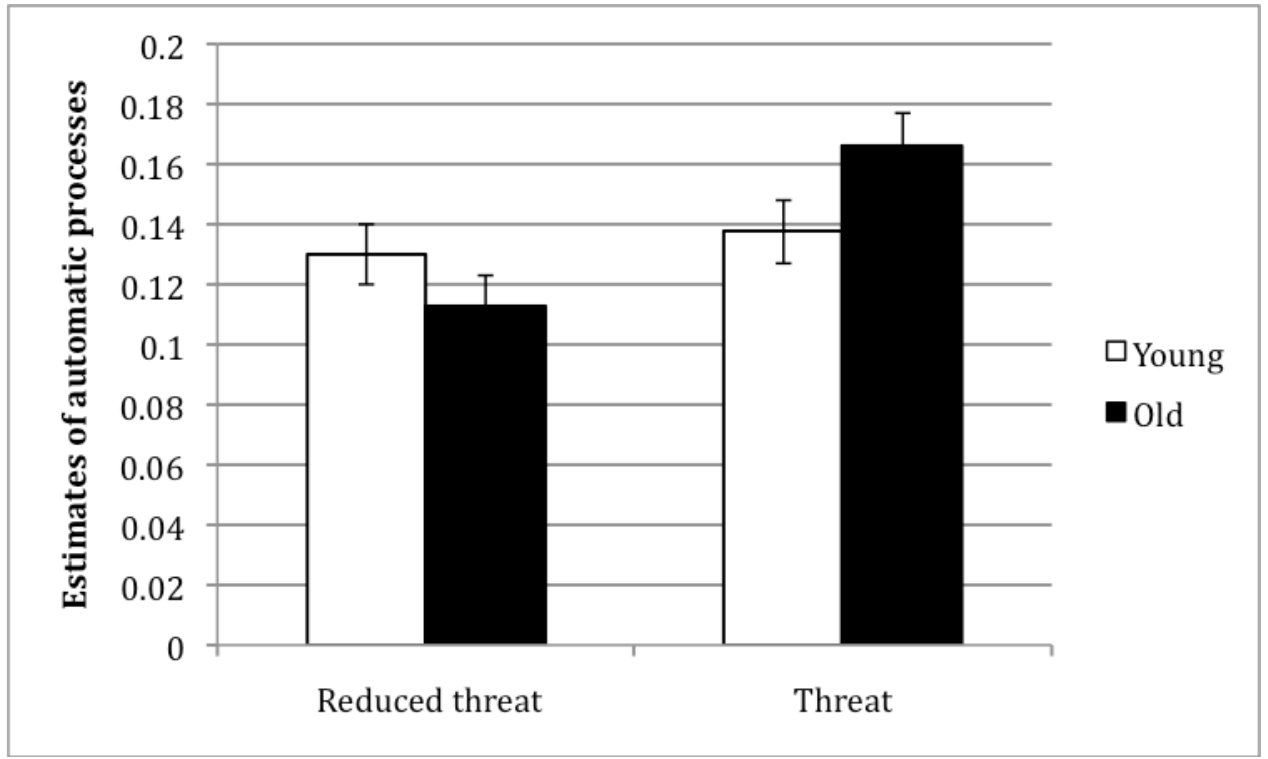

Fig. 3. Estimates of automatic influence in cued recall by threat condition and age group. Error bars indicate standards errors of the mean. 